\title{
Good medicine, human rights and the rights of doctors
}

\section{$\boldsymbol{V}$ Len Doyal, ${ }^{1}$ Lesley Doyal, ${ }^{2}$ Daniel Sokol ${ }^{3}$ EDITOR'S \\ CHOICE}

Over the last two decades, the impact of bioethics on medical training and practice has been immense. All medical students in the UK are now required to study the theory and application of the ethical and legal duties of clinical care. Similarly, practising clinicians are expected to demonstrate an acceptable level of understanding of these duties to qualify for professional memberships and fellowships and to succeed in reviews of fitness to practise. Articles on medical law and ethics regularly fill the pages of the most prestigious medical journals. Throughout the world, the departments of health and medical associations publish a wide range of ethicolegal guidelines, and medical litigation seems forever on the rise.

For these reasons, a good understanding of key issues and developments in ethics and law applied to medicine is vital to individual practitioners in managing their professional lives and delivering an appropriate standard of care. To help achieve these goals, the journal will begin this month a new section to address the ethical and legal dilemmas that are now an integral part of clinical practice. The goal of the section is not to replicate the more abstract material already found in many bioethics journals. Rather it will focus on matters of topical interest and do so in ways that reflect the personal views of experienced healthcare professionals. An accompanying editorial will introduce each commissioned article and place it in context. We want this section to make a significant practical difference to what doctors think and do about their patients and their own professional and personal lives. Eventually, we hope that this part of the journal will evolve into an international forum where doctors can raise ethical and legal problems to encourage ongoing debate.

\footnotetext{
${ }^{1}$ Barts and The London, Queen Mary, University of London, London, UK and School of Medicine, University of East Anglia, Norwich, UK; ${ }^{2}$ Department of Sociology, Centre for Health and Social Care, University of Bristol, Bristol, UK; ${ }^{3}$ St George's, University of London, Centre for Medical and Healthcare Education, London, UK

Correspondence to: Professor Len Doyal, 708 Willoughby House, Barbican, London EC2Y 8BN, UK; I.doyal@qmul.ac.uk
}

In this issue, the questions to be explored concern respect for human rights in clinical care. The ethical guidelines that doctors are expected to follow make it clear that the individual rights of patients should be taken seriously. Human rights legislation within the UK and the European Community and the various declarations of human rights sponsored by the United Nations and other international organisations apply just as much to the practice of medicine as they do to other arenas of life. ${ }^{1}$ Within the UK, for example, the Department of Health and NHS Trust hospitals make their own emphasis on human rights clear in their internal publications and regulatory procedures. ${ }^{2}$

More specifically, the clinical duties of care to protect life and health, to respect autonomy and to do both without being unfairly discriminatory are reflections of broader human rights that are widely recognised. ${ }^{3}$ Some doctors also believe that their duties of care extend beyond the wards and consultation rooms and into the realms of politics, since good healthcare cannot be divorced from the basic levels of social, economic and environmental support to which citizens also have a right. Whatever the similarities and differences between those who believe in the existence of human rights, these beliefs will impact upon the perception of what good medicine is and who is entitled to it.

Yet this emphasis on the importance of respect for human rights can place pressure on the moral character of doctors. For example, it is not always clear how to interpret the practical implications of particular rights such as informed consent and equal treatment or indeed to ascertain whether or not these rights even exist. At other times, there may be conflict between the right of patients to be protected from harm and their right to have their own beliefs respected. Jehovah's Witnesses who refuse life-saving blood transfusions are a good illustration of this. Doing the right thing in difficult clinical circumstances can demand courage, prudence and levels of personal and professional maturity that not all individuals possess. ${ }^{4}$
Moreover, these are not the best of times for many doctors. They face personal and professional hurdles in the progress of their careers. Indeed they may well feel that their own human rights are at times compromised by professional demands. Their employers owe them a duty of care - again, of protection, respect and equal treatment-that they may not always honour. Doctors who feel that they have been unjustly accused of unprofessional conduct by healthcare management-or indeed their own colleagues-will understand the stress that this can produce. Indeed, patients themselves may actually or potentially threaten the personal and professional wellbeing of doctors. Coming from diverse educational, emotional and social backgrounds, some "difficult" patients can stretch the capacity of their doctors for empathy and respect to breaking point. Patients who are abusive to staff or other patients can be especially demanding.

Evidence shows that this complex professional environment can contribute to depression and burn out, along with alcohol abuse, marital difficulties and general unhappiness with clinical work. ${ }^{5}$ Although different clinicians may respond, and may be predisposed to respond, in different ways, some will exhibit more personal resilience than others. ${ }^{6}$ However, contrary to the beliefs of some idealistic medical school applicants, the fact remains that being a doctor in the 21st century is not all champagne and roses.

Dr Julian Sheather argues in this issue (see page 148) that matters can be made worse for young doctors if they are subjected to unjustified and personally damaging criticism of their work. ${ }^{7}$ It is common for some patients to blame doctors for things over which they have no control, such as long waits. Criticism is also common in the media where commentators and activists of various persuasions make generalised accusations about the medical profession as a whole. One of us remembers writing a piece for an English broadsheet newspaper saying that the month of August, when newly qualified doctors start their clinical work, is no more dangerous for patients than any other month. The published headline conveyed the opposite message: "Danger: white coats. Be very afraid, says Daniel K. Sokol". When confronted, the editor replied "There would be no story otherwise!".

Of course, doctors will sometimes make mistakes and may not give their patients optimal care. But, as Dr Sheather makes clear, it is all too easy for those with little 
experience of the practical and personal complexities of healthcare delivery to make unjustified criticisms, thereby adding to any negative feelings that doctors may have about who these commentators are and what they do.

Some of these feelings might be relieved if doctors had a better understanding of the fundamentally moral character of good medical practice. Doctors and other health workers do not simply effect cures or manage disease and disability (although of course these are important activities in themselves). When they practise in a morally sensitive way, they enable their patients to flourish as human beings. This is because they make it possible for them to optimise their interaction with other individuals and hence their participation in the wider society. Recall the verses of the English poet John Gay:

Nor love, nor honour, wealth nor power

Can give the heart a cheerful hour

When health is lost.

Thus, good medical practice is, in itself, the embodiment of respect for human rights and should be recognised as such. Dr Sheather concludes that both doctors and human rights activists appreciate the fundamental importance of health, but that the apparent conflict between the two groups may result from differing perspectives-doctors tend to have a "micro" view focusing on individual patients, whereas activists have a broader sociopolitical understanding of healthand that the tension can be resolved with greater understanding from each party.

In choosing what to do with our lives, there are many virtuous tasks we might undertake, and the practice of good medicine ranks among the most important of these. This is an important message for all doctors to remember in whatever moral challenges they face in their professional practice.

We welcome comments from readers about Dr Sheather's arguments, as well as their own views on the human rights of both patients and doctors. It should not be forgotten that, while many may feel that patients and doctors have a right to be treated with optimal levels of respect and protection, the law in many countries falls far short of this standard. Should we submit and adjust, or should we demand change?

Competing interests: None.

Postgrad Med J 2009;85:113-114. doi:10.1136/pgmj.2008.077420

\section{REFERENCES}

1. British Medical Association. The impact of the human rights act on medical decision making. London: BMA, 2007.

2. Department of health. Human rights. http://www.dh gov.uk/en/Managingyourorganisation/ Equalityandhumanrights/Humanrights/index.htm (accessed 20 Feb 2009).

3. Doyal L. The moral foundation of the clinical duties of care: needs, duties and human rights. Bioethics 2001;15:520-35

4. Gardiner P. A virtue ethics approach to moral dilemmas in medicine. J Med Ethics 2003;29:297-302.

5. Firth-Cozens J. Doctors, their wellbeing, and their stress. It's time to be proactive about stress. BMJ 2003;326:670-1.

6. McManus IC, Keeling A, Paice E. Stress, burnout and doctors' attitudes to work are determined by personality and learning style: a twelve year longitudinal study of UK medical graduates. BMC Med 2004;2:29.

7. Sheather J. Health professionals and human rights campaigners: different cultures, shared goals. Postgrad Med J 2009;85:148-151.

\section{Warwick University short course: techniques and applications of molecular biology}

13-16 July 2009

A 4-day course for those in the medical profession wishing to improve their understanding of the principles and applications of genetic engineering techniques. Optional accreditation leads to a masters level postgraduate award.

Details: Dr Charlotte Moonan, Department of Biological Sciences, University of Warwick, Coventry, CV4 7AL; tel: +44 (0) 247652 3540; email Charlotte.Moonan@warwick.ac.uk; website www.warwick. ac.uk/go/bioscienceshortcourses). 